\title{
ANÁLISE DA EFICÁCIA DOS MÉTODOS DE ACONDICIONAMENTO DE ESCOVAS DENTAIS DE ESCOLARES DE UMA INSTITUIÇÃO BÁSICA DO INTERIOR NORDESTINO
}

\author{
ANALYSIS OF THE EFFECTIVENESS OF METHODS OF PACKING DENTAL BRUSHES FOR \\ SCHOOLS IN A BASIC INSTITUTION IN THE NORTHEAST INTERIOR
}

Samuel José Amaral de Jesusa, Eliane Oliveira da Silvaa, Keyte Evans Carneiro de Almeida, Luara Leal Góes, Thais Mascarenhas Lima Carvalho Báfica

Universidade Estadual de Feira de Santana E-mail: samueljoseamaral@gmail.com

\begin{abstract}
RESUMO
A escova dentária é o instrumento mais utilizado pela população para remoção do biofilme dentário. Entretanto, muitas pessoas se esquecem de que a higienização e o armazenamento da escova são fundamentais para que a mesma não venha a se tornar um veículo transmissor de microrganismos possivelmente patogênicos. Com objetivo de analisar a eficácia dos métodos de desinfecção e acondicionamento das escovas, destacar os prejuízos do armazenamento inadequado e incentivar a Educação em Saúde, este projeto foi realizado em um colégio privado da Região Nordeste do país, com alunos do 30 ano do Ensino Médio, que contribuíram no preenchimento de questionários e na doação de suas escovas para análise laboratorial. No laboratório foram encontradas diversas colônias de fungos e bactérias, com destaque para o gênero Staphylococcus. O questionário permitiu observar que grande parte dos estudantes realizava corretamente a higienização de suas escovas (64\%). Conclui-se que, independentemente da forma de armazenamento, as escovas apresentarão algum tipo de contaminação, sendo imprescindível a aplicação da educação continuada nas comunidades, como $92 \%$ dos alunos assim concordaram.
\end{abstract}

Palavras-chave: Escova Dentária; Desinfecção; Acondicionamento.

\begin{abstract}
The toothbrush is the instrument most used by the population for the removal of tooth biofilm. However, many people forget that cleaning and storing the brush are essential so that it does not become a vehicle for transmitting possibly pathogenic microorganisms. Aiming to analyze the effectiveness of brush disinfection and conditioning methods, highlight the harm caused by inadequate storage and encourage Health Education, this project was carried out in a private school in the Northeast region of the country, with students from the 3rd year of high school who contributed to filling out questionnaires and donating their brushes for laboratory analysis. In the laboratory, several colonies of fungi and bacteria were found, with emphasis on the Staphylococcus genus. The questionnaire allowed us to observe that most students correctly cleaned their brushes $(64 \%)$. It is concluded that, regardless of the form of storage, the brushes will present some type of contamination, being essential the application of continuing education in communities, as $92 \%$ of students agreed.
\end{abstract}

Keyword: Toothbrush; Disinfection; Packaging. 


\section{V.10 N.1 (2022) ISSN: 2317-434X}

\section{INTRODUÇÃO}

A evolução da ciência e a adoção de novas tecnologias originaram uma abordagem científica diferenciada, que culminou na criação e utilização de instrumentos mecânicos para higienização do corpo, com a meta de evitar possíveis doenças e melhorar a qualidade de vida dos indivíduos, alterando assim o perfil epidemiológico. No que diz respeito à higiene bucal, o instrumento mais utilizado e conhecido pela população é a escova dentária, uma vez que se trata de um objeto de fácil acesso pela população, diretamente ligado à cultura e condições da sociedade (QUEIROZ et al., 2013; QUEIROS; PASSOS, 2019).

Mesmo a escova dental sendo o instrumento mais utilizado pela comunidade para remoção do biofilme bacteriano e à higienização da boca, muitas pessoas ainda não sabem o quanto este pode servir como veículo para doenças, geralmente causadas por microrganismos patogênicos, em especial os fungos e bactérias (ALVEZ REZENDE, 2015; MASSONI et al., 2015; COSTA; CARVALHO; CARVALHO, 2017).

Alguns estudos explicitam que a escova não deve ficar exposta ao meio ambiente nem acondicionada em estojos, pelo fato de que tais situações podem desencadear no aparecimento e crescimento microbiano. Outras pesquisas demonstraram que as cerdas precisam estar protegidas contra qualquer patogenicidade, reduzindo-se o risco de contaminação, fato que provoca uma série de discussões sobre o tema aqui proposto (PEDRAZZI et al., 2009; QUEIROS; PASSOS, 2019).

É comum entre as famílias a utilização de métodos coletivos de acondicionamento de escovas dentais, como por exemplo, o recipiente porta-escovas, que proporciona o contato direto entre os instrumentos, que possivelmente estão infectados, gerando um ambiente favorável às infecções, uma vez que o porta-escovas costuma ser fechado e úmido. Tal situação é interligada às condições físicas do local onde estes recipientes estão inseridos (geralmente no banheiro), o que acaba por facilitar a proliferação microbiana que provém de aerossóis, a exemplo das Staphylococcus e enterobactérias (FERREIRA et al., 2013; BUSATO et al., 2015).

Sendo assim, o presente estudo possui a seguinte pergunta de investigação: Quais são os métodos de desinfecção e acondicionamento de escovas dentais mais eficazes contra a proliferação de microrganismos patogênicos à saúde bucal?

O interesse pelo tema se deu, primeiramente, pela curiosidade de conhecer e analisar a vulnerabilidade da população em adquirir infecções advindas dos métodos de armazenamento das escovas dentais; uma vez que, culturalmente, todos são induzidos a crer que a escova é um recurso utilizado para eliminação total dos microrganismos da cavidade oral, e não vetores destes que podem ocasionar riscos à saúde humana.

Desse modo, o estudo tem como objetivo analisar a eficácia dos diferentes métodos de desinfecção e acondicionamento das escovas dentárias, de alunos de um colégio privado do interior nordestino, na busca por destacar os prejuízos do armazenamento inadequado e, dessa forma, incentivar a promoção da Educação em Saúde.

\section{MATERIAIS E MÉTODOS}

Esta pesquisa foi submetida e aprovada pelo Comitê de Ética em Pesquisa (CEP) da Faculdade Nobre de Feira de Santana (FAN). A mesma se baseia em um estudo exploratório, de caráter quantitativo e transversal, realizado em um colégio privado do Nordeste do país, entre escolares da $3^{\text {a }}$ série do Ensino Médio.

Utilizou-se uma amostra de 30 alunos, com tempo de utilização das escovas dentais de 1 a 3 meses, que foram convidados a participar do estudo de forma voluntária, mediante a autorização prévia dos pais e/ou responsáveis. Sendo assim, quanto aos critérios de inclusão, participaram os estudantes da referida instituição de ensino, de ambos os sexos, com idades entre 16 e 18 anos, matriculados no último ano do Ensino Médio, que faziam parte de uma única turma, e foram autorizados pelos pais ou responsáveis a contribuírem ao estudo. Dessa forma, não participaram os alunos de outras séries, ou aqueles que não compareceram com o termo de autorização / consentimento assinado.

Durante o convite inicial, foi realizada a explanação sobre o tema e objetivos do projeto, a todos os participantes. Na ocasião, foi sugerida uma data para aplicação dos questionários, que seria a mesma da entrega dos termos de consentimentos. Salientando que os estudantes participantes foram convocados a trazer suas escovas de dente, para análise microbiológica no laboratório.

Assim, na data proposta, os pesquisadores aplicaram um questionário com 16 questões objetivas, para obtenção das características sociodemográficas e hábitos higiênicos, junto com a apresentação do Termo de Consentimento Livre e Esclarecido (TCLE). Também foram recolhidas as escovas dentárias dos participantes.

Os itens apresentados no questionário envolviam: variáveis sociodemográficas (sexo, idade), tempo de uso da escova entregue durante a ação, número de escovações realizadas por dia, período (em minutos) de cada escovação, período (em meses) para troca desse 


\section{V.10 N.1 (2022) ISSN: 2317-434X}

instrumento, quantidade de pessoas com quem compartilha o banheiro, procedimentos que adota para secagem da escova após o uso. Também foi verificado se o sujeito realiza a higienização com o antisséptico bucal, se tem noções sobre os microrganismos que danificam o biofilme dentário, se consideram importante o emprego da Educação em Saúde como um instrumento para conscientizar os escolares e a comunidade sobre o tema.

No Laboratório de Microbiologia, da Faculdade Nobre de Feira de Santana, as escovas de dente foram banhadas em um tubo de ensaio com $5 \mathrm{~mL}$ de água destilada e esterilizada. Posteriormente, $0,2 \mathrm{~mL}$ desta suspensão foi semeada nos meios de cultura Ágar Nutriente (NA) e Ágar Sabouraud (SAB), incubada a 37 ${ }^{\circ} \mathrm{C}$ e $28^{\circ} \mathrm{C}$. O tubo com suspensão foi incubado a $37{ }^{\circ} \mathrm{C}$ por 24 horas e posteriormente difundido em placas de Petri contendo os meios NA e Ágar MacConkey (MAC), com a expectativa de observar o crescimento de microrganismos.

Por outro lado, a verificação das informações obtidas nos questionários se realizou através da criação de um banco de dados no programa Microsoft Office Excel, através do sistema operacional Windows. Nele, foi possível observar o comportamento das variáveis, com ênfase à distribuição de frequências, o que culminou na geração de tabelas, com informações concernentes aos questionários.

Vale salientar que, na execução do estudo, não foram utilizadas informações que permitissem identificar quaisquer sujeitos ou instituições. Sendo assim, foram obedecidos os pressupostos elencados na Resolução $\mathrm{n}^{\mathbf{0}}$. 466/2012, do Conselho Nacional de Saúde (CNS) (BRASIL, 2012).

\section{RESULTADOS E DISCUSSÃO}

Dentre os 30 alunos que compuseram a entrevista, $62 \%$ pertenciam ao sexo feminino, enquanto $38 \%$ eram do sexo masculino, sendo que a faixa etária predominante foi de 16 e 17 anos (74\%). Desses indivíduos, 45\% vinham usando a escova há cerca de 1 mês, $25 \%$ há 2 meses e $30 \%$ há 3 meses, destacando que a maioria praticava a escovação por cerca de 5 vezes ao dia (57\%), em um período que varia de 2 a 3 minutos $(46 \%)$, e realizava a troca apenas de 3 em 3 meses (45\%).

A maioria dos profissionais de Odontologia recomenda que a troca do dispositivo dentário seja realizada a cada 3 meses, ou mensalmente, de acordo com o quadro clínico. Sendo que essa também é uma recomendação do Ministério da Saúde, e da Agência Nacional de Vigilância Sanitária - ANVISA. Nesse ínterim, também é importante observar quando as cerdas começarem a perder a cor e a conformidade, aspectos que contribuírem para a troca. Em relação à durabilidade, ressalta-se o fato de que as escovas podem ser manuais ou automatizadas, além da habilidade para realizar a escovação. Salientando que a qualidade dos materiais de higiene bucal exerce influência, com destaque ao dentifrício (PEDRAZZI et al., 2009; BRASIL, 2017; LIMA; SANTOS; SOUZA, 2019; OLIVEIRA, 2020).

Vale destacar que grande parte dos entrevistados costumava compartilhar o mesmo banheiro com 1 a 3 pessoas (77\%), e que acondicionavam a escova nesse cômodo, com uso do protetor de cerdas. Quando questionados sobre os procedimentos realizados após cada escovação, cerca de $65 \%$ afirmaram que batem a escova na borda da pia e/ou secam esse instrumento na toalha, destacando que exatos $64 \%$ realizavam a higienização de suas escovas com o antisséptico bucal.

Quanto aos métodos de acondicionamento, Pedrazzi et al. (2009) explicam que a escova não deve ficar exposta ao meio ambiente nem acondicionada em estojos, pelo fato de que tais situações podem desencadear no aparecimento e crescimento bacteriano.

$\mathrm{O}$ protetor de cerdas encontra-se disponível em forma parcial (para proteger apenas a cabeça da escova) ou total (que envolve por completo). Entretanto, é discutível o fato de que o mesmo também possa ocasionar infecções, caso não seja higienizado com frequência para conferir a devida proteção às cerdas, o que pode ocasionar prejuízos à saúde do usuário. Nesse ínterim, é de suma importância afirmar que não foram encontrados artigos na literatura que comprovem a real eficácia desse equipamento.

Em suma, é fundamental que as escovas sejam acondicionadas em ambiente arejado, na posição vertical, de modo que facilite a secagem e, consequentemente, a diminuição do nível de fungos e bactérias. Caso mais de uma escova tenha que ser armazenada num mesmo local, é fundamental que elas sejam mantidas separadas, para que os micro-organismos não venham a ser transferidos entre tais instrumentos, evitando-se a proliferação microbiana e infecção cruzada (LUCIANO; SPECHT; DITTERICH, 2017; GONÇALVES et al., 2019).

Feitosa (2020) apresenta algumas recomendações sobre os cuidados com a escova após o uso, que coincide com a atuação de boa parte dos estudantes, tais como: lavar esse dispositivo com água corrente e bater o cabo na pia, para remoção do excesso de água; guardar a escova na posição vertical e em local seco, a fim de que as cerdas sequem com mais facilidade, devendo estar distante do vaso sanitário. No entanto, a referida dentista explica que não é apropriado secar as cerdas com papel higiênico ou toalhas, pois esses itens podem ser veículos de contaminação. Quanto ao protetor de cerdas, é 


\section{V.10 N.1 (2022) ISSN: 2317-434X}

recomendado que o mesmo seja utilizado se houver orifícios para a ventilação.

Lima, Santos e Souza (2019) destacam que as capas protetoras de cerdas podem favorecer a proliferação microbiana, pelo fato de que as mesmas proporcionam um ambiente quente e úmido, que é favorável para boa parte dos fungos, vírus e bactérias.

Sobre a higienização, Soares et al. (2010) explicam uma finalidade primordial do processo de descontaminação das escovas. Eles abordam que "a descontaminação deve ser usada como método para evitar transmissão microbiana entre indivíduos de uma mesma família ou entre pessoas que compartilham o mesmo espaço para armazenamento das suas escovas" (p. 10).

Retomando o resultado de que $64 \%$ dos participantes utilizavam solução bactericida para desinfecção, concorda-se com Gonçalo e Mialhe (2009), que destacam que a utilização de agentes químicos se popularizou no mercado. Hoje em dia, há uma série de produtos com potencial bactericida, pois, segundo os mesmos, "tais recursos são considerados eficientes métodos" que "favorecem o controle das infecções provocadas pela contaminação nas escovas, além de apresentarem baixo custo" (p. 57). Porém, se o sujeito não tiver acesso a esses produtos / soluções, recomenda-se inserir a escova em água fervente por 10 minutos. Ressaltando ainda que os antissépticos não substituem a escovação, nem o uso do fio dental (LIMA; SANTOS; SOUZA, 2019; OLIVEIRA, 2020).

Percebe-se que boa parte dos estudantes demonstrou preocupação com a desinfecção e o subsequente acondicionamento de suas escovas, supondose que os mesmos têm noções dos prejuízos que os microrganismos podem trazer ao biofilme dental e, em alguns casos, à saúde humana como um todo. Nesse contexto, os dispositivos dentais ocasionam desequilíbrio quando se tornam um reservatório para proliferação microbiana.

Segundo Alves Rezende (2015), diante de tal situação, as escovas contaminadas ampliam o risco de doenças bucais e sistêmicas, como septicemias, alterações respiratórias, gastrintestinais, renais e cardiovasculares. São doenças geralmente ocasionadas por bactérias e leveduras entéricas, que costumam se alojar nas cerdas, em especial quando esse dispositivo é acondicionado de forma coletiva. Ressaltando que o tempo de uso também influencia o processo de contaminação.

A análise laboratorial comprovou que todas as escovas trabalhadas na amostragem apresentavam contaminantes. Isso porque foi possível observar, nas placas de Petri usadas na pesquisa, a formação de colônias de fungos e bactérias, com destaque aos microrganismos do gênero Staphylococcus.

Destaca-se, por exemplo, o estudo de Chibinski et al. (2011), que analisaram escovas de 30 crianças com necessidades especiais. Os autores observaram o crescimento de bacilos Gram-negativos, estreptococos, bem como leveduras do gênero Candida, todos pertencentes às escovas estudadas.

Ferreira et al. (2012) analisaram escovas de 40 indivíduos aparentemente saudáveis, com idades entre 3 e 58 anos. Depois das análises, verificou-se a contaminação bacteriana nas cerdas, com o crescimento das seguintes espécies: Escherichia coli, Klebsiella pneumoniae, Streptococcus pyogenes e Staphylococcus coagulose negativo. Sendo assim, nota-se que os microrganismos podem ser de origem da flora bucal, como do ambiente em que as escovas foram acondicionadas. Independente da origem, todos podem influenciar no desenvolvimento de patógenos.

Não foi à toa que muitos dos alunos demonstraram interesse na implantação da Educação em Saúde na comunidade escolar com enfoque à conscientização, não somente a respeito da limpeza da boca, mas também sobre os cuidados que devem ser empregados com as escovas de dente antes e após cada escovação (em uma média de $92 \%$ dos participantes).

Vale salientar que toda escova deve ser leve, de fácil limpeza e impermeável quanto à umidade, para evitar infecções, reinfecções e outras formas de contaminação. Sendo que o papel do cirurgião-dentista é algo crucial nesse contexto, para orientar sobre o armazenamento e desinfecção, além de promover a saúde bucal por meio da Educação em Saúde, que é uma ferramenta fundamental para que os hábitos saudáveis sejam adotados com melhor eficácia (ALVES REZENDE et al., 2015; JESUS, 2015).

Como explicam Garcia, Amaral e Cimardi (2015), a educação e a motivação dos cidadãos quanto à saúde bucal são de grande importância para promover o desenvolvimento de uma consciência crítica e provocar o interesse pelos cuidados com a boca. Nesse ínterim, o aconselhamento de profissionais qualificados também se torna crucial para orientar sobre o tipo de escova e o melhor perfil de escovação, conforme as particularidades do paciente, além das formas de acondicionamento, o período de substituição e os modos de desinfecção.

\section{CONCLUSÃO}

As escovas de todos os estudantes apresentaram algum tipo de contaminação, o que mostra o quanto é imprescindível a realização da Educação Continuada em Saúde para orientar os escolares e a comunidade, no que 


\section{V.10 N.1 (2022) ISSN: 2317-434X}

diz respeito aos cuidados com esse instrumento tão eficaz na remoção do biofilme dentário.

Os dados presentes na literatura apresentaram diversos métodos de acondicionamento das escovas, com a sua efetividade comprovada, mas não foi encontrado um consenso ou uma prevalência que permitisse expor, nesta produção, qual seria o método mais adequado para essa finalidade, ou até mesmo para fazer a desinfecção.

O mais importante é cuidar criteriosamente da escova, realizar a sua desinfecção com produto antisséptico, retirar o excesso de água após a lavagem do instrumento e acondicionar de forma a proteger especialmente as cerdas, recordando-se a necessidade da troca periódica, sempre observando a sua conformação, e o acompanhamento com um cirurgião-dentista.

Esse estudo serve de referência para realização de novas investigações, sendo sugerida uma análise microbiológica mais criteriosa que determine espécimes microbianas, e que permita discutir profundamente sobre as principais doenças resultantes do uso de escovas contaminadas.

\section{REFERÊNCIAS}

ALVES REZENDE, M. C. R. et al. Descontaminação de escovas dentárias: métodos e eficácia. Archives of Health Investigation, v. 04, n. 01, p. 50-57, 2015. https://archhealthinvestigation.com.br/ArcHI/article/view/882.

BRASIL. Ministério da Saúde. Agência Nacional de Vigilância Sanitária. Diretoria Colegiada. Resolução RDC no. 142, de 17 de março de 2017. Dispõe sobre a regularização de produtos de higiene pessoal descartáveis destinados ao asseio corporal, que compreendem escovas e hastes para higiene bucal, fios e fitas dentais, absorventes higiênicos descartáveis, coletores menstruais e hastes flexíveis. Brasília, 2017. Disponível em: https://www.in.gov.br/web/guest/materia/-

/asset_publisher/Kujrw0TZC2Mb/content/id/20833442/do1-

2017-03-20-resolucao-rdc-n-142-de-17-de-marco-de-2017-

20833350. Acesso em: 26 jul. 2021.

Ministério da Saúde. Conselho Nacional de Saúde. Resolução n⿳0 466, de 12 de dezembro de 2012. Brasília, 2012. Disponível

$\mathrm{em}$ https://bvsms.saude.gov.br/bvs/saudelegis/cns/2013/res0466_1 2_12_2012.html. Acesso em: 26 jul. 2021.

BUSATO, C. A.; CAVAZZOLA, A. S.; ORTEGA, A. O. L.; GUARÉ, R. O.; NETO, A. S. Utilização do hipoclorito de sódio na descontaminação de escovas dentais: estudo in vitro. Revista de Odontologia da UNESP, v. 44, n. 06, p. 335-339, 2015. https://doi.org/10.1590/1807-2577.04214.

CHIBINSKI, A. C. R. et al. Descontaminação de escovas dentais utilizadas por crianças portadoras de necessidades especiais: analises microbiológicas. Revista Sul-Brasileira de Odontologia, v. 08, n. 02, p. 145-152, 2011. https://www.redalyc.org/articulo.oa?id=153018891005.

COSTA, J. O.; CARVAlho, F. S.; CARVAlho, C. A. P. Desinfecção e acondicionamento de escovas dentais: conhecimento e atitudes de acadêmicos de enfermagem. Archives of Health Investigation, v. 06, n. 09, p. 418-422, 2017. http://dx.doi.org/10.21270/archi.v6i9.2222.
FEITOSA, A. V. N. C. Cuidados com a saúde bucal em tempos de pandemia. Informativo 01. Núcleo de Assistência Estudantil (NAE/CSHNB), Jun. 2020. Disponível em: https://www.ufpi.br/arquivos_download/arquivos/INFORMAT IVO_NAE_1_vers\%C3\%A3o_final20200615114958.pdf. Acesso em: 26 jul. 2021.

FERREIRA C. A.; SAVI, G. D.; PANATTO, A. P.; GENEROSO, J. S.; BARICHELLO, T. Avaliação microbiológica das cerdas de escovas dentárias de uso frequente. Dental Press Journal of Orthodontics, v. 17, n. 4, p. 72-76, 2012. https://doi.org/10.1590/S217694512012000400016 .

FERREIRA, G. T. S.; FREIXINHO, A. B. S.; MACHADO, S. J.; MIASATO, J. M. Verificação da contaminação e forma de armazenamento de escovas dentais de um grupo de adolescentes de uma escola da rede privada de ensino. Revista de Odontologia da Universidade Cidade de São Paulo, v. 25, n. 01, p. 6-10, 2013. https://doi.org/10.26843/ro_unicid.v25i1.313.

GARCIA, C. J.; AMARAL, M. A.; CIMARDI, A. C. B. S. Avaliação clinico-gengival de diferentes dentais. Arquivos do MUDI, v. 19, n. 01, p. 57-68, 2015. https://periodicos.uem.br/ojs/index.php/ArqMudi/article/view/ 29047.

GONÇALO, C. S.; MIALHE, F. L. Contaminação das escovas dentais: uma revisão critica da literatura. Revista Periodontia, v. 19, n. 03 , p. $56-63,2009$.

GONÇALVES, G. H. et al. Contaminação, meios de desinfecção e armazenamento da escova dental: revisão de literatura. Revista de Iniciação Científica e Extensão, v. 02, n. 04, p. 219-227, 2019. https://revistasfacesa.senaaires.com.br/index.php/iniciacaocientifica/article/view/261.

OLIVEIRA, K. C. C. (Org.). IFMA. Instituto Federal Maranhão. 


\section{V.10 N.1 (2022) ISSN: $2317-434 X$}

Campus São Luís - Centro Histórico. Coronavírus: cuidados com a saúde bucal para evitar a transmissão da doenças. São Luís: IFMA, 2020.

JESUS, S. J. A. O papel da educação em saúde frente às implicações da Atenção Básica: do profissional à comunidade. Revista Interfaces: Saúde, Humanas e Tecnologia, v. 02, n. 07, p. 1-9, 2015. http://dx.doi.org/10.16891/2317.434X.143.

LIMA, J. D. A.; SANTOS, J. C.; SOUZA, I. F. A. C. Higienização e armazenamento das escovas dentais: uma percepção do conhecimento e hábitos dos docentes de Odontologia do Centro Universitário Tiradentes (UNIT-PE). Cadernos de Graduação: Ciências Biológicas e da Saúde, v. 04, n. $02, \quad$ p. $117-139$, 2019. https://periodicos.set.edu.br/facipesaude/article/view/7748.

LUCIANO, H. X.; SPECHT, A. C.; DITTERICH, R. G. Avaliação do acondicionamento de escovas dentais de préescolares nos Centros Municipais de Educação Infantil e Escolas Municipais de Colombo-PR. Revista Odontológica do Brasil Central, v. 26, n. 77, p. 47-52, 2017. https://www.robrac.org.br/seer/index.php/ROBRAC/article/vie w/1019.

MASSONI, A. C. L. T. et al. Condições físicas e acondicionamento de escovas dentais de pré-escolares. Arquivos em Odontologia, v. 51, n. 02, p. 96-103, 2015. http://dx.doi.org/10.7308/aodontol/2015.51.2.05.

PEDRAZZI, V.; SOUZA, S. L. S.; OLIVEIRA, R. R.; CIMÕES, R.; GUSMÃO, E. S. Métodos mecânicos para o controle do biofilme dentário supragengival. Revista Periodontia, Taubaté, n. 19, n. 03, p. 26-33, 2009.

QUEIROS, E. C. F.; PASSOS, M. A. N. Aspectos de contaminação e descontaminação das cerdas de escovas dentais. Revista Ciências e Odontologia, v. 03, n. 01, p. 1-5, 2019. http://revistas.icesp.br/index.php/RCO/article/view/433.

QUEIROZ, F. S. et al. Avaliação do perfil de armazenamento e descontaminação das escovas dentais. Revista de Odontologia da UNESP, v. 42, n. 02, p. 89-93, 2013. https://doi.org/10.1590/S1807-25772013000200004.

SOARES, P. V.; FONSECA, L.; BRANDÃO, C. F.; JUIZ, P. J. L. Avaliação da contaminação de escovas dentais por microrganismos e da efetividade de antissépticos na sua descontaminação. Revista Brasileira de Pesquisa em Saúde, Vitória, v. 12, n. 03, p. 5-10, 2010. https://periodicos.ufes.br/rbps/article/view/820. 